\title{
Analysis of Modern Methodological Approaches to Pricing in the Field of Secondary Resources
}

\author{
Tatyana V. Velikanova* \\ Irina K. Kiforenko \\ Andrey A. Tolstonogov
}

Samara State Technical University, Samara, Russia; *Corresponding Email: tanja.vel@mail.ru

Doi:10.5901/mjss.2015.v6n6s7p289

\begin{abstract}
Establishing a price for waste is an important component in the pricing policy of the enterprise and the element of economic regulation in the field of waste. Insufficient number of works devoted to pricing of secondary resources makes it a highly relevant study. The lack of available pricing methods for waste production and consumption, which are re-involved in the economic turnover as a raw material, hinders decision-making of enterprises on establishing prices on recyclables. The paper reveals the relevance of the topic; the factors affecting the price of secondary resources are discussed. In line with the traditional classification methods of cost, income and market, authors identify and analyze the methods used in the practice or those having prospects for practical application in the field of secondary resources, their features are underlined.
\end{abstract}

Keywords: price, pricing factors, recycling waste, pricing models, waste, secondary resources, resource potential

\section{Introduction}

Improvement of the whole system, covering the collection, transportation, storage and processing of waste is an integral part of environmental and economic policy of the country and an important factor to maintain the ecological safety of territories. The most effective and open way of regulation of the industry is the use of market-based instruments aimed at promoting the safe management of waste and the involvement of secondary resources into the economy. Formation of market institutions of environmental sphere requires a long-term state program, involving not only the adjustment of the existing legislation but profound institutional transformation associated with changes in rent relations and the development of effective methods of pricing.

The objective of establishing the best producer prices for products and services, or in the case of waste management - the price of the waste of production and consumption, can be considered as both in terms of marketing and the market economy in general, and from the point of view of economic and mathematical methods. Currently, however, despite the amount of research related to the development of specific methods of establishing long-term, economically justified prices for secondary resources requires more in-depth theoretical and practical study.

The limited demand for secondary raw materials (i.e. recyclables) and products made with recycled materials is caused by the insufficient level of environmental education and awareness, low-grade civil position in relation to the protection of the environment on the one hand, and the emerging shortage of stable volumes of recyclables on the market as a consequence - on another. Factors of state regulation include benefits and subsidies to enterprises of waste processing, licensing and state supervision in the field of waste management, tax incentives for recycling and waste sorting, and other issues of waste management, those of a subject to legislative regulation. From the point of view of maximizing the public good, fair pricing follows the implementation of the 3R principle (i.e. reduce, reuse and recycle), which indirectly contributes to raising environmental awareness in the society. The importance of such knowledge in the field of waste is mentioned, for example, in the study of Samiha (2013).

If we consider the issue on the use of waste from the point of view of producers, it must be noted that the long-term goal of all businesses is to maximize profits while ensuring an acceptable level of risk that does not threaten the integrity of the company. One way of gaining an additional profit is more the effective waste management, including its separate collection, sorting, recycling or reuse. These operations can be carried out as by the third-party organizations, or by the enterprise itself. And, if necessary, to sell waste to third parties for further processing. No matter of what method is chosen, the company will inevitably face the issue of pricing. 
Thus, the objective determination of prices for waste and secondary resources is necessary to both commercial organizations and government agencies, making the development of approaches to pricing in the secondary resources an urgent task.

\section{Factors and Methods of Pricing}

\subsection{Factors of pricing}

Let us consider the factors that influence the price of waste and secondary resources. Among the factors of pricing are production factors, demand factors, competitive market factors, factors of commodity properties, factors of product distribution channels, factors of state control, factors of the strategic development of the enterprise (Kiforenko, 2010). The most important factors in pricing of waste production and consumption are the costs of waste management, limited demand and competitor behavior, the quality of secondary raw materials received from waste, and the factors of state regulation.

The costs of waste management include the costs of sorting and organizing separate waste collection, transportation costs, costs of environmental payments (i.e. payment for waste disposal in the environment), etc. Also here can be attributed the ecological and economic damage resulting from the decline in the quality of the environment while placing the waste (Gridina et al., 2014).

The problem of pricing can be mathematically formulated as a problem of mixed integer nonlinear programming, with the budget and transport costs being known for each consumer who makes a purchase in the company, the cost of purchasing and transportation for which is at a minimum level and if these costs do not exceed its budget. Companies also need to choose where to place the outlets and what price to assign as to maximize profits (Plyasunov \& Panin, 2012). In order to solve this problem, the methods of local search are developed: simulated annealing - SA and a variable neighborhood search - VNS (Diakova \& Kochetov, 2012).

In terms of practical application, of interest is the statement of the problem of pricing in using a 'Stackelberg game' approach (i.e. Stackelberg leadership model) with unequal players (Stackelberg, 1934). This mathematical model is an example of solving economic and mathematical problem of determining the equilibrium price in the market conditions. The leader makes the first move, and his decision determines the system limitations of other players. At the top level is an enterprise manufacturing uniform products, sets prices in each of its sales divisions. On the lower level, each consumer chooses one of the points of sale, where the transport costs and the cost of purchasing goods in the amount are of minimal level. Purchase is made in the case of a suitable budget allowance of the consumer. It is required that each company determines those prices for which the income of producer is maximum possible - the factory pricing strategy (Plyasunov \& Panin, 2012).

In addition to the factory pricing strategy, the following two strategies are usually covered: the uniform pricing, when all the points of sale set the same price, and discriminatory pricing - the strategy in which each point of sale can set different prices for different customers (Plyasunov \& Panin, 2012). Applying these approached to the secondary resources, the user selects one of the points of sales of the processed waste that can be placed either directly in the storage facilities, processing or temporary placement of waste (i.e. landfills, waste sorting, transfer stations) or can be placed outside these objects. High transportation costs (compared to the cost of sorting) make the stated problem rather perspective.

\subsection{Pricing methods}

There are three basic approaches to pricing: 1) Cost based - takes into account the cost of processing and disposal (leveling aside the damage caused to the environment); 2) Profit based - takes into account the income derived from the sale of waste for its subsequent use as secondary raw materials (including on the basis of the calculation of the resource potential, the differential rent), and 3) Market based - takes into account the supply and demand balance and customers' preferences and is based on interviews, expert estimates and experiments.

\subsection{Cost based method}

Cost method is based on determining the value of secondary resources by evaluating the costs of extraction of valuable components from waste, as well as an average profit rate. The price of waste is defined as follows: 
$\mathrm{P}=\mathrm{C}+\mathrm{PR}$,

with $\mathrm{P}$ - the price per ton of recycled resources;

$\mathrm{C}$ - the unit cost of collection, transportation, removal, sorting and other operations on the separation of secondary resources from waste;

PR - profit rate.

The cost of removal may be unnecessarily inflated because of the imperfect system of collection and sorting of waste, and because of the low content of nutrients in the total mass of waste. The price may be adjusted by payments for environmental pollution (according to the established legislation of the Russian Federation of rates per ton of waste of a certain class of danger), and can also be taken into account averted ecological and economic damage caused by waste disposal in the environment. Cost method does not account for market conditions and can only be effective to determine the minimum acceptable price.

\subsubsection{Evaluation by means of differential rent}

Fundamentals of the theoretical approach to the assessment of natural resources through rents in a market economy and the methods of determining the economic benefit from their exploitation were laid in the works of such economists as the L.V. Kantorovich, B.C. Nemchinov, N.P. Fedorenko, T.S. Khachaturov, K.G. Hoffman, and many other scholars.

Value of waste is determined by the value of the secondary resources that can be extracted, and extra profits earned by the enterprise-polluter due to higher-quality resource being used, that is brought by their differential rent. Shimova and Sokolovskiy (2005) indicate that the basis of payments for natural resources should be their economic assessment on the basis of differential rent. Differential rent shows the economic benefits receives by the subject of the economic system due to more favorable natural characteristics of the considered resource (i.e. its better quality, more profitable locations, etc.). Determination of differential rent enables to account for the effect of unequal resource properties resulting from territorial features on the productivity of social labor. Then, the price for the resource can be defined as follows:

$$
P=R+C,
$$

with $\mathrm{P}$ - the price of the resource, or the amount of payment for it;

$\mathrm{R}$ - economic assessment on the basis of differential rent;

$\mathrm{C}$ - the cost of development and reproduction of the resource.

Differences as waste going to process, also affect the productivity, therefore, they must be considered in a similar manner. Shimova and Sokolovskiy (2005) indicate that in a market economy, the pricing depends on the balance of supply and demand in the goods, and the basis of the market price is the price of production (i.e. recycling), which allows to compensate the cost of production (i.e. waste management) and provide the average profit.

\subsubsection{The method of determining the price on the basis of the resource potential}

From the point of view of the resource potential, the pricing models were considered by such authors as Il'yinykh et al. (2012), Korotaev et al. (2011), Leontiev et al. (2012), and others. An approach based on an assessment of resource potential is essentially used in the article, Leontiev et al. (2012) for determining the level for the price of technogenic raw materials taking into account the content of useful components in the raw material, the coefficient of recovery of useful components, prices of the useful component in the finished product, unit costs for processing of raw materials and the effect of the distribution coefficient between producers and consumers of raw materials. The total price of the waste is defined as follows:

$$
P w=\left(\sum \operatorname{Com}_{i} C_{e x t i} P_{i}-U C_{\text {proc }}\right) \times C_{e f f},
$$

with $P w$ - the price of waste (i.e. technogenic raw materials);

$\mathrm{Com}_{i}$ - composition of i number of useful component if waste;

$C_{e x t i}$ - coefficient of extraction of i number of useful component in the finished product;

$P i$ - price of i number of useful component in the finished product;

$U C_{\text {proc }}$ - the unit cost of processing 1 ton of raw materials;

$C_{\text {eff }}$ - the effect of the distribution coefficient between producers and consumers of raw materials.

Such an approach is being considered by Kuznetsova et al. (2011) in relation to oil sludge - an industrial type of 
waste and is based on the methodology of JSC "Samaraneftegaz" (enterprise standard number 16 CH-STP-P14, 2006). Under this approach, the assessment of the cost of the oil sludge takes into account their physico-chemical properties that determine the mass fractions of petroleum products produced after processing. Marker oil is used as the base oil, the price of which is adjusted depending on the density and the mass fraction of sulfur.

The advantage of this approach is the accuracy of determining the price of the waste taking into account the content and quality of mineral components. As the shortcomings can be noted the need for laboratory testing of each tailings pond and the absence of revenue from the sale of other products derived from oil sludge, such as bitumen.

Similarly, one can determine the value of household waste, depending on their morphological structure. The limitation is the fact that the morphological composition of household waste is subject to strong fluctuations in within one settlement.

In general, the price of waste can be determined on the basis of its economic assessment (i.e. resource potential) and the cost of transportation and processing:

$\mathrm{PW}=\mathrm{R}-\mathrm{C}_{\mathrm{tr}}-\mathrm{C}_{\mathrm{rec}}+\mathrm{F}+\mathrm{S}$,

with $P w$ - the price of waste;

$\mathrm{R}$ - economic assessment of waste;

$\mathrm{C}_{\mathrm{tr}}$ - transportation cost of waste;

$\mathrm{C}_{\text {rec }}-$ costs of sorting and recycling;

$\mathrm{F}$ - fee for placing unprocessed waste (i.e. tailings) in the environment according to the current legislation;

$\mathrm{S}$ - savings on environmental payments (i.e. payments of the project participants for the environmental impact; other than fees for placement of unprocessed waste). The environmental payments are payments of the project participants for the impact on the environment, in addition to payments for waste disposal $F$, implemented by disposal and recycling facilities in accordance with legislation (Ladoshkin et al., 2011).

$R=\sum \operatorname{Com}_{i} C_{\text {exti }} P_{i}$,

$\mathrm{Com}_{i}$ - composition of i number of useful component if waste;

$C_{\text {ext } i}$ - coefficient of extraction of i number of useful component in the finished product;

$P_{i}$ - price of the i-th component is extracted.

At a substantial cost on transportation and processing of final products, the cost of secondary resources might be too low, or even negative, showing the inefficiency of the processing technology in question, or too expensive transportation.

\subsubsection{Income method based on environmental charges}

This method is based on the same approach towards the resource potential and costs (i.e. the difference between benefits and costs is based on the accounts of environmental charges), but offers in additional mechanism of calculating the profits between the company-supplier of secondary resources, and the company-consumers (Ladoshkin et al., 2011).

Let us consider an example in which part of raw materials (i.e. natural resources) in the production cycle is replaced with the secondary resource. In this case, the price of recyclables is determined by the sum of the benefits from the use of recyclable materials and savings on payments for environmental pollution and the costs of transporting the resource. Price depends on who will provide transportation - if it is the company that is using the recyclables, the price will be as follows:

$P^{1}=-\mathrm{Fwd}-\mathrm{S}+T I^{2}-\frac{c t r}{2}$

with Fwd - fee for waste disposal;

$S$ - savings on environmental charges;

$T l^{2}$ - the total income from the project for supplying recyclables to be used instead of natural resources;

$\mathrm{C}_{\mathrm{tr}}$ - the cost of transporting recyclables.

The total income from the project $\mathrm{TI}$ is the cost of resources that will be replaced by recyclables $\mathrm{Cr}$, charges of waste disposal and recycling facilities, changes in product prices as a result of switching to recyclables $\Delta \mathrm{P}$, changes in operating costs at the plant by the use of new technology $\Delta \mathrm{Ct}$ and savings on environmental charges (Ladoshkin et al., 2011). That is, the total income of the two participants in the project (i.e. the company that uses recyclables - $\mathrm{Tl}^{1}$ and supplier of recycled $-\mathrm{Tl}^{2}$ ) can be determined by the formula:

$T I=C r+F w d \pm \Delta P \pm \Delta C t+S$. 
If the delivery is made by the supplier of recyclables, the price of it is determined by the formula:

$P^{2}=-F w d-\mathrm{S}+T I^{2}+\frac{C t r}{2}$.

Thus, in this model, as in the previous one, the transportation cost and benefits from the use of recycled materials are considered. In addition, the total income of participants in the project is calculated, which shows the economic effect of the introduction of new technology.

\subsubsection{Resale price method}

This method is a market method. The price is determined as the difference between the revenue of resale of the goods and the costs incurred in this case, with the price of the original purchase is not considered, but the final result is compared to the average rate of profit.

$\mathrm{C}=\mathrm{Rev}-\mathrm{C}_{\text {res; }}$ C $>\mathrm{Pr}$,

with $\mathrm{C}$ - cost per ton of recycled materials;

Rev - revenue from the resale of goods;

$\mathrm{C}_{\text {res }}-$ costs incurred in the resale of secondary raw materials;

$\mathrm{Pr}_{\mathrm{r}}$ - profit rate.

The cost for resale except for transport and commercial expenses can be taken into account and the cost of sorting of waste, if the operation is provided by the terms of the contract. This method is based on an assumption that the price of the waste for sale is known in advance.

\section{Conclusion}

Difficulties in setting prices for household waste will be determined by variational morphological composition of waste, the possible seasonal features and technological difficulties of extraction of useful fractions from the waste due to the undeveloped separate waste collection system.

The mathematical formulation of the problem of pricing gives an idea of its meaning, but in practice it is difficult to use due to the difficulty in determining the budget for each potential customer (but it is possible by means of surveys and market research), and also because of the significant impact of non-price factors affecting the decision making process. However, under certain assumptions, it well applicable for preliminary calculations for justification of administrative decisions. Cost based method determines only the minimum acceptable price, which, however, can be adjusted taking into account the environmental charges and damage caused to the environment by waste disposal. Its advantage is simplicity and clarity for the consumer (although it does not guarantee an acceptable price).

Using the method of determining the price based on differential rent can take into account heterogeneity of the initial resources used and different composition of useful components. The most convenient to use in practice are the methods of determining the price on the basis of the resource potential and those taking into account environmental charges. In the first case, the method enables to differentiate the cost of the feedstock, depending on the mineral content, determined based on laboratory analysis. This ensures that the consumer pays for desired properties of the goods, but does not account for environmental payments as stipulated by the legislation of the Russian Federation. The second method does not have this drawback and provides simultaneous sharing of profits between the supplier and the consumer - current user of secondary raw materials, which can be useful at the conclusion of agreements on the use of secondary resources in production. Resale price method can also be used in setting prices for secondary resources, if sales revenue known in advance, that is, the buyers are known. However, this method does not account for the true value of the useful components contained in the waste, and may underestimate rates due to low revenue of the seller.

It should be noted that for the companies engaged in production activities in the field, not related to the treatment of waste, the extraction of the resource potential from waste usually helps to reduce the environmental charges and environmental damage, but does not bring substantial profits. In these circumstances, the establishment of an effective price for the waste contributes to the transfer of waste to specialized organizations engaged in the processing and their rational use. This, in turn, will contribute to the revitalization of the investment process in the field of secondary resources, enhance recycling and, ultimately, the integration of the Russian economy into the world market.

\section{References}

Diakova, Z., \& Kochetov, Yu. (2012), A double VNS heuristic for the facility location and pricing problem. Electronic Notes in Discrete Mathematics, 39, 29-34. 
Gridina, M.S., Velikanova, T.V., \& Pimenov, A.A. (2014), Ecological-and-economic substantiation of placements of the recycling enterprises of oil slimes on basis of mathematical models. Moscow: MITHT.

Il'yinykh, G.V., Korotayev, V.N., \& Slyusar', N.N. (2012), Modern methodological approaches to the analysis of morphological composition of solid household waste in order to assess their resource potential. Ecology and Industry of Russia, 7, 40-45.

Kiforenko, I.K. (2010), Increase of economic efficiency of industrial enterprises through improved marketing activities. PhD thesis. Samara: Samara State Technical University

Korotaev, V.N., Wiseman, Y.I., Grigoriev, V.N., \& Slyusarev, N.N. (2011), Improving the efficiency of extraction of the resource potential of municipal solid waste. Ecology and Industry of Russia, 12, 22-26.

Kuznetsova, M.S., Pivsaev, V.Y., Pimenov, A.A., Ermakov, V.V., Tupitsina, O.V., Suhonosova, A.N., Ryumin, N.V., Samarin, O.A., Uvarov, N.A., Gladyshev, N.G., Burlaka, V.A., \& Bykov, D.E. (2011), Differentiation oil sludge collectors based on their resource potential. Ecology and Industry of Russia, 12, 30-33.

Ladoshkin, A.I., Mayorova, I.A., \& Kharitonova, E.A. (2011), Development and optimization of management decisions: tutorial. Samara: Samara State Technical University

Leontiev, L.I., Bryantseva, O.S., \& Dyubanov, V.G. (2012). Technogenic metallurgical resources raw potential usage under conditions of the zinc industry modernization. Economy of region, 3, 166-173.

Plyasunov, A.V., \& Panin, A.A. (2012), The problem of pricing. Part 1. Exact and approximate algorithms for solving. Discrete Analysis and Operations Research, 19 (5), 83-100.

Samiha, B. (2013), The importance of 3R principle of municipal solid waste management for achieving sustainable development. Mediterranean Journal of Social Sciences. 4 (3), 129-135.

Shimova, O.S., \& Sokolovsky, N.K. (2005), Environmental economics. Tutorial. Moscow: Infra-M.

von Stackelberg, H.F. (1934), Markform und Gleichgewicht. Vienna: Julius Springer. 